\author{
Original Article
}

\title{
Relationship between Pathological Occlusal Changes and the Signs and Symptoms of Temporomandibular Dysfunction
}

\author{
Ana de Lourdes Sá de Lira (iD, Maria Karen Vasconcelos Fontenele (iD
}

Department of Pediatric Dentistry and Orthodontics, Universidade Estadual do Piauí - UESPI, Area of Integrated Clinic, Parnaíba, Piauí, Brazil

Cite this article as: de Lourdes Sá de Lira A, Vasconcelos Fontenele MK. Correlation between Pathological Occlusal Changes and the Signs and Symptoms of Temporomandibular Dysfunction. Turk J Orthod 2020; 33(4): 210-5.

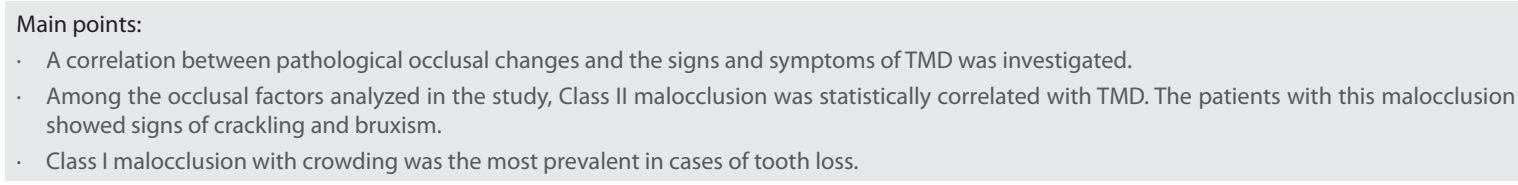

\section{ABSTRACT}

Objective: This study aimed to investigate whether there is a correlation between pathological occlusal changes and the signs and symptoms of temporomandibular dysfunction (TMD).

Methods: This cross-sectional, quantitative, non-randomized clinical trial was conducted on 150 participants. We examined adult patients of both genders with occlusal interference, malocclusion and dental absence in the posterior region of the dental arch that were associated or not associated with painful symptoms. The questionnaire was administered, and the intra- and extra-oral clinical examination was performed on each patient, including the evaluation of the temporomandibular joint (TMJ) to investigate the presence of dysfunction.

Results: The mean age of the participants was 33 years $( \pm 2.3)$, and $103(68.7 \%)$ of them were women and $47(31.3 \%)$ were men. Tooth loss and malocclusion were more prevalent in females. Tooth loss showed a statistically significant association with all the signs and symptoms of TMD ( $p=0.02)$. Patients with multiple teeth losses experienced preauricular pain during mandibular opening and closing. There was no association between malocclusion with tooth loss and the signs and symptoms of TMD in 65 patients $(p>0.05)$

Conclusion: Only in the patients with Class II malocclusion there was a significant association with 2 signs of TMD (crackling and bruxism). There was no association between malocclusion and tooth loss with the signs and symptoms of TMD. The signs and symptoms of TMD were more frequent in the patients who presented multiple teeth loss without malocclusion.

Keywords: Malocclusion, occlusion, temporomandibular joint dysfunction syndrome

\section{INTRODUCTION}

Temporomandibular joint dysfunction (TMD) presents clinical, muscular, and articular symptoms related to the stomatognathic system. It has a multifactorial etiology, and it is related to structural, neuromuscular, occlusal factors (dental loss, dental wear, maladaptive dentures, cavities, improper restorations, premature contact of restorations, inclination of teeth toward the space created by tooth loss, bruxism, nail-biting, hand-jaw support, digit or pacifier sucking) and traumatic or degenerative lesions of the temporomandibular joint (TMJ) $(1,2)$.

Symptoms may occur spontaneously, but in general, they are aggravated by masticatory function. They are usually unilateral and are located close to the ear, the angle of the mandible, or the face and temporal area, with 
restricted muscle movements, tenderness to palpation, and possibly heterotopic pain when trigger points are detected (3).

Pain is the most common symptom, and women are more affected than men. Some possible reasons for this involve psychosocial, psychological, behavioral, hormonal, and structural factors. TMD symptoms appear to be more severe and last longer in women, increasing the chance that they will seek treatment. Symptoms have a negative impact on the quality of life of the patient, impairing work activities, school, sleep, and appetite (4).

Both genders are affected equally between the ages of 20 and 40 , with little clinical evidence in children. The signs of TMD in children are mild, from no evidence progressing to more severe dysfunction as adults. The low prevalence in elderly individuals can be explained by the fact that with advancing age, symptoms of other more serious diseases are more salient than those of TMD, and this reduces the likelihood of seeking treatment $(5,6)$.

The literature is strong and consistent in support of the role of other factors, such as psychosocial and genetic issues, as well as muscle-related overload, in the pathophysiology of TMD. It is worth mentioning that the loss of posterior teeth, a lower number of teeth, and edentulousness have been associated with TMD symptoms. Non-occlusion on at least one side leads to an increased likelihood of developing myofascial pain (7).

Although occlusion is commonly considered to be a major risk factor for TMD, there is limited understanding of the causal relationship between the occurrence of TMD symptoms and occlusion and of the possible role of the different aspects of occlusion in the etiology of TMD (8).

For this reason, it is necessary to follow up on patients by performing occlusal adjustments and orientation to obtain removable dentures as a replacement for permanent teeth that are lost, ensuring an improvement in aesthetics, speech, and chewing, i.e., in the patient's quality of life. The high prevalence of TMD and the negative outcomes that are associated with several other morphofunctional problems justify the development of this research.

As a hypothesis, it is believed that occlusal factors should not be considered the most important factors in the etiology of TMD. It is necessary to take a broad view of its etiological factors and to recognize occlusion as just one of these factors, which may or may not have an influence on TMD, depending on the patient's characteristics. Therefore, the aim of the study was to investigate whether there was a correlation between pathological occlusal changes and the signs and symptoms of TMD.

\section{METHODS}

A cross-sectional, quantitative, non-randomized clinical intervention study was carried out after approval by Committee Research Ethics at the State University of Piauí - CEP / UESPI with the decision number 1.978.081. The number of patients attended to per month in the Clinical School of Dentistry (CSD) of the State Univer- sity of Piauí in the city of Parnaíba-PI was considered as the target population. For that, an arithmetic average of the number of visits was calculated for the period between August 2017 and June 2018 , resulting in 310 patients per month. Based on the proposed data and considering a sampling error of $5 \%$ in addition to a $95 \%$ confidence level, the minimum sample size needed to represent the assisted population was 160 participants (9).

Adult patients of both genders with occlusal interferences, such as premature dental contact points or any type of malocclusion (biprotrusion, crowding, crossbite, open bite, Angle Class I, Class II, and Class III), associated or not associated with dental absence in the posterior region (of one tooth or teeth in any posterior hemi-arch of both arches), with or without painful symptomatology, were included in the study. We excluded patients who had already used orthodontic appliances or had a history of TMD treatment, patients with cognitive deficiency, and those who did not wish to participate in the study.

During the experiment, some of the patients did not continue treatment and finally a total of 150 participants, were included for further analysis, of whom 97 were women and 53 were men. Convenience sampling was used, which consisted of selecting the participants consecutively as the individuals arrived at the data collection site.

The team, made up of 2 researchers, had a workload of 36 hours, divided between theoretical discussion of the variables and codes used, the criteria of examination, and practical discussion. The experiment simulated the different conditions and situations that the professionals would encounter during their practical work in the diagnosis of occlusal interferences, dental losses, malocclusion, pain, and TMD in 30 patients who received routine care at the CSD, according to the methodology described in another publication (10).

Between December 2017 and May 2018, the patients were selected as they sought dental treatment on Mondays, Wednesdays, and Fridays, during both shifts at the CSD. After the signing and authorization of the informed consent form, the questionnaire that had been developed for the study of each case was applied. The physical examination for the intra- and extra-oral evaluation of each patient was then performed, including an analysis to investigate the presence of TMD. Dental signs, malocclusions, and TMD were recorded in the clinical file (the 3 symptoms of muscle fatigue, preauricular pain and TMJ pain), along with 7 dental indicators, including click (a clear, strong, and short sound), crackling (a long and rough sound), mandibular displacement, limited mouth opening, mandibular locking, tightening, and bruxism. The presence of these symptoms and signs is suggestive of TMD because they can be associated with occlusal conditions, trauma, emotional distress, and parafunctional activities.

Mandibular displacement was considered as the deviation from the dental midline during opening the mouth. Mouth-opening limitation was measured by the distance between the incisal edges of the upper and lower central incisors, $52.85 \pm 7.41 \mathrm{~mm}$ for men and $48.34 \pm 5.64 \mathrm{~mm}$ for women. 
Clinically, mandibular locking was measured by the partial or total interruption of mandibular movement. As the mandible is a rigid arch, a lock on one side produces chin deviation toward the homologous side, creating a rotational movement. In total locking, the mouth opens up to the limit of the lock.

Tightening and bruxism were detected by the wear on the incisors and canines and were associated with pain in the TMJ.

To detect joint noise, manual palpation, and bilateral auscultation of the TMJ were done using a stethoscope. The patients opened and closed their mouth several times, following the verbal prompt of the examiner, so that it was possible to determine the presence or absence of noise and the type of noise. The manual palpation of the masticatory muscles and the TMJ evaluation followed the recommendations of Santos et al. (11). This palpation was performed as a complement to the clinical evaluation to analyze the muscle condition.

The patients received follow-up at the CSD for 1 year. During the study, the researchers gave educational lectures on the subject.

The importance of maintaining oral hygiene was emphasized to prevent tooth loss and TMD.

The sample of patients with malocclusion was referred to the specialization clinic in the city of Parnaíba for orthodontic treatment. When necessary, in situations of occlusion interference, occlusal adjustment was performed at the end of orthodontic treatment in patients who presented "spots" after an occlusal test with carbon paper. Those with tooth loss who needed removable dental prostheses were referred to the CSD for oral rehabilitation.

\section{Statistical Analysis}

The data were tabulated using The Statistical Package for Social Sciences version 21.0 software (SPSS Inc., Chicago, IL, USA), and descriptive statistics (frequency and distribution) were measured. Chi-square tests were used to verify the association between symptoms, sex, and causes. A pilot study was performed on 20 patients. The patients who did not fit the sample to test the proposed methodology were also assisted by the CSD. As a result, its viability was observed, with no need for adjustments. To assess intra- and inter-examiner reproducibility, $10 \%$ of the total sample was double examined by each of the examiners, and the Kappa coefficients for the agreement of intra- and inter-examiners were 0.88 and 0.87 , respectively.

\section{RESULTS}

The mean age of the participants was $33 \pm 2.3$ years, and 103 $(68.7 \%)$ of them were women and $47(31.3 \%)$ were men. The results were showed in tables 1-3 with their respective descriptions. In patients who had malocclusion associated or not associated with tooth loss, dental interference was present, and occlusal adjustment was performed in 90 patients after orthodontic treatment. The distribution of tooth loss and malocclusion in

Table 1. Distribution of tooth loss, multiple teeth loss, and malocclusion in relation to gender tested by chi-square test

\begin{tabular}{|c|c|c|c|c|c|c|c|}
\hline Variables & $\mathbf{N}$ & Women & Men & $\begin{array}{l}\text { Chi-square value } \\
\text { and } p \text { value }\end{array}$ & Superior arch & Inferior arch & Both arches \\
\hline Tooth loss & 20 & 11 & 9 & $\begin{array}{l}x^{2}=0.20 \\
p=0.65\end{array}$ & $\begin{array}{l}\text { Women: } 8 \\
\text { Men: } 2\end{array}$ & $\begin{array}{l}\text { Women: } 3 \\
\text { Men: } 7\end{array}$ & \\
\hline Multiple teeth loss & 40 & 29 & 11 & $\begin{array}{l}x^{2}=12.81 \\
p=0.01^{* *}\end{array}$ & $\begin{array}{c}\text { Women: } 4 \\
\text { Men: } 1\end{array}$ & $\begin{array}{l}\text { Women: } 9 \\
\text { Men: } 3\end{array}$ & $\begin{array}{l}\text { Women: } 16 \\
\text { Men: } 7\end{array}$ \\
\hline Malocclusion & 25 & 19 & 6 & $\begin{array}{l}x^{2}=5.40 \\
p=0.02^{*}\end{array}$ & & & \\
\hline
\end{tabular}

Table 2. Frequency of the sample distribution based on the questionnaire

\begin{tabular}{|c|c|c|c|c|c|c|c|}
\hline $\begin{array}{l}\text { Signals/ } \\
\text { symptoms }\end{array}$ & $\begin{array}{c}\text { Total } \\
n=150\end{array}$ & Women & Men & $\begin{array}{l}\text { Tooth loss } \\
n=20\end{array}$ & $\begin{array}{l}\text { Multiple teeth } \\
\text { loss } n=40\end{array}$ & $\begin{array}{l}\text { Malocclusion } \\
n=25\end{array}$ & $\begin{array}{l}\text { Malocclusion+multiple } \\
\text { teeth loss } n=65\end{array}$ \\
\hline Click & 60 & 47 & 13 & 11 & 39 & 8 & 2 \\
\hline Crackling & 26 & 20 & 6 & 5 & 17 & 3 & 1 \\
\hline Muscle fatigue & 44 & 35 & 9 & 6 & 24 & 9 & 5 \\
\hline Mandibular displacement & 50 & 34 & 16 & 10 & 20 & 7 & 13 \\
\hline Mouth-opening limitation & 26 & 21 & 5 & 2 & 13 & 6 & 5 \\
\hline Tooth tightening & 64 & 45 & 19 & 13 & 23 & 8 & 20 \\
\hline Bruxism & 50 & 32 & 18 & 10 & 22 & 3 & 15 \\
\hline Preauricular pain & 48 & 36 & 12 & 7 & 21 & 8 & 12 \\
\hline TMJ pain (opening and closing) & 42 & 30 & 12 & 5 & 20 & 8 & 9 \\
\hline
\end{tabular}


Table 3. The results of Chi-square test regarding the signs/symptoms and the variables

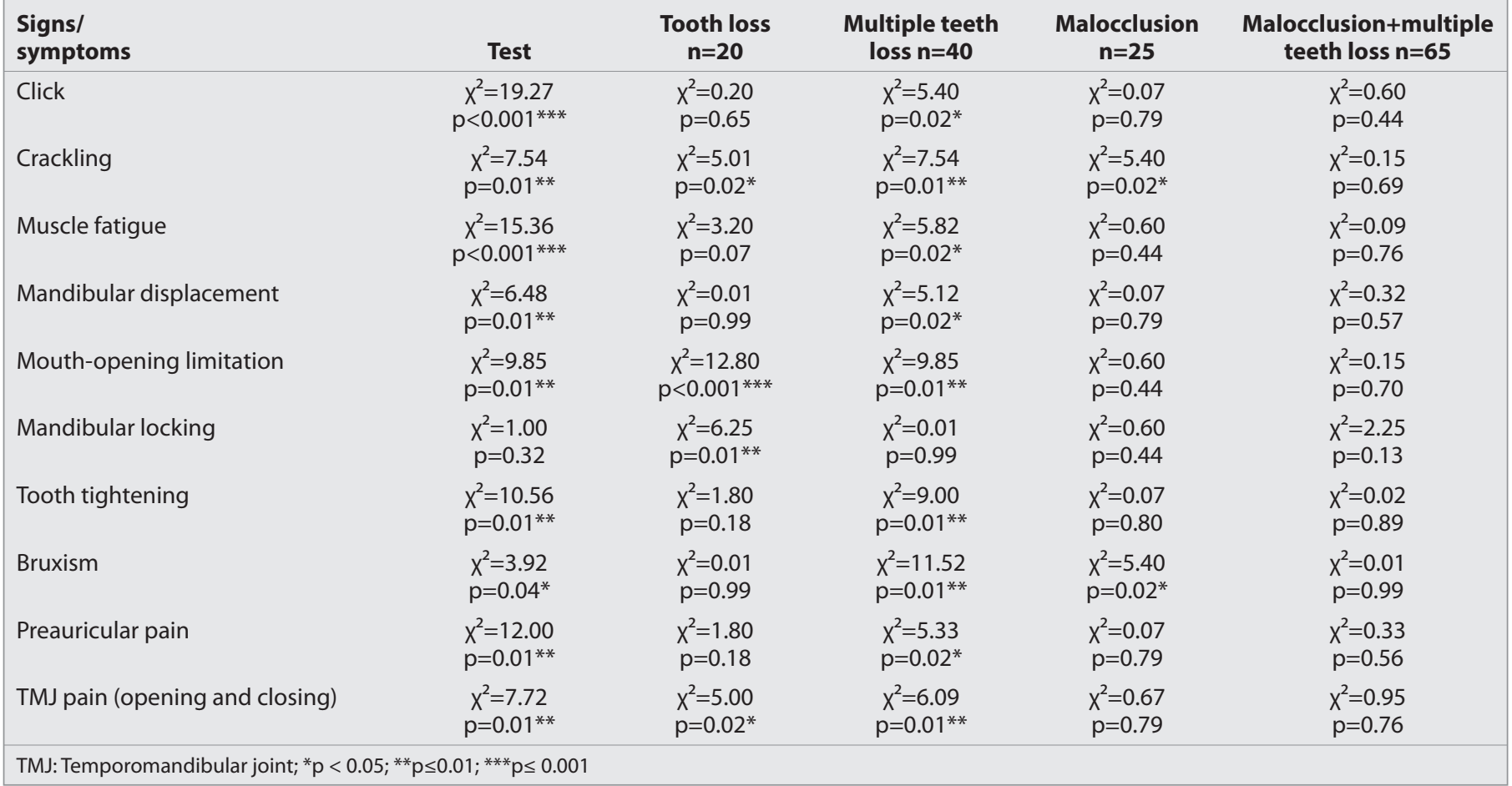

relation to gender and chi-square test was showed in Table 1. Among 29 women, there were multiple teeth loss in the posterior region, ranging from 4 to 6 teeth. In 16 women, there was a teeth loss in both arches. Table 2 shows the frequency of the sample distribution. Table 3 shows the chi-square test results for the signs, symptoms, and variables. There was a significant predominance of women in relation to tooth loss and malocclusions (Table 1).

It was found that there were differences in the association between gender and dental absence or malocclusion in the 7 signs and 3 symptoms of TMD $(p<0.05)$. This scenario indicates the rejection of the null hypothesis because of significant differences between the observed and expected frequencies (Table 2). There was a greater association of the female gender with the signs and symptoms of TMD. Tooth loss showed a statistically significant association with all the signs and symptoms of TMD. All the patients with multiple teeth loss experienced preauricular TMJ pain and pain during mandibular opening and closing (Table 2). However, in tooth loss, only crackling, limited mouth opening, and mandibular locking were observed (Tables 1-3).

In the patients who presented only malocclusion, 16 cases of Class II, 7 of Class I with anterior crowding, and 2 of Class III with posterior crossbite were observed. No patient had an anterior open bite. There was a significant association $(p=0.02)$ with 2 signs of TMD (crackling and bruxism) only in the patients who presented Class II malocclusion. There was no association between the 65 cases of malocclusion with tooth loss and the signs and symptoms of statistically significant TMD (Table 3). There were 42 patients with Class I malocclusion with anterior crowding (17 with tooth loss and 25 with multiple teeth loss), 21 patients with Class II (7 with tooth loss and 14 with multiple teeth loss), and 2 patients with Class III malocclusion associated with multiple teeth loss.

\section{DISCUSSION}

Functional, structural, and psychological factors characterize the complex multifactorial etiology of TMD. Occlusion is treated not only as the contact relationship between the teeth but also as a dynamic, morphological, and functional relationship between all the components of the stomatognathic system that has a great influence on chewing, swallowing, and speech. The authors believe that occlusion plays a limited role; however, it cannot be underestimated (12-15).

In this study, there was an association between muscular pain and TMJ, click, and crackling in some clinical situations, such as dental loss and malocclusions (Tables 2 and 3), corroborating Costa et al. (16). They observed that $80 \%$ of the patients with TMD presented positive responses to TMJ sounds, muscle fatigue, or pain during chewing, headache and pain in the cervical region, occlusal interference, and associated malocclusions.

Although other authors have stated that joint noises are frequent, the absence of joint noise cannot be a determining factor of joint normality. There is a relationship between TMD and occlusal factors that may predispose, trigger, or perpetuate this dysfunction, and the occlusal analysis of the patients should not be neglected (16).

In particular, the multiple loss of posterior teeth was quite expressive (Tables 1-3), suggesting an association with the signs and symptoms of TMD. The loss of posterior support is considered to be one of the few dental factors that had some consisten- 
cy of evidence in the literature as a cause of TMJ pain and TMD. This was observed by Landi et al. (17) when they stated that the most prevalent occlusal factor in TMD patients was the absence of 5 or more posterior teeth. This kind of tooth loss could lead to joint problems, particularly the risk of cracking and dislocation of the articular disc. Some authors have reported that the patients with greater tooth loss in support areas were more affected by myofascitis of the lateral pterygoid muscle, capsulitis, and partial anterolateral disc displacement, which may accelerate the development of TMJ degenerative diseases (17-19).

In this study, it was observed that the patients who presented multiple tooth loss without malocclusion showed significant signs and symptoms of TMD, such as click, crackling, muscle fatigue, mandibular displacement, limited mouth opening, mandibular locking, tooth tightening, bruxism, preauricular pain, and TMJ pain (opening and closing). It is worth mentioning that the patients with tooth loss associated with malocclusion did not show any significant correlation with TMD signs and symptoms. This suggests that orthodontic treatment alone will not treat this dysfunction. Oral rehabilitation is indicated to restore the correct masticatory function and muscle balance. Such observations have been made by other authors who concluded that invasive dental therapy, such as orthodontic treatment, is not recommended for the management or prevention of TMD, and its need should be analyzed with caution by practitioners $(17,18)$.

In the study by Lemos et al. (20) and Teixeira et al. (21), the malocclusion was not associated with the presence of TMD or the appearance of clinical signs. Among the occlusal factors analyzed in the study, Class II malocclusion was statistically correlated with the need for treatment and TMD, which corroborates our studies because Class II showed significant signs of TMJ crackling and tooth creaking. When malocclusion was associated with multiple teeth loss, Class I with dental crowding was more prevalent, but the signs and symptoms of TMD were not statistically significant, although they were observed in all the malocclusions studied (Tables 2, 3).

In a prospective longitudinal study, an increase in the prevalence of TMD symptoms was found in a group of patients with Class II malocclusion. According to these authors, the type of occlusion may play a role as a contributing factor in the development of TMD signs and symptoms, although this influence is difficult to quantify and predict (22).

In a systematic review of the association between malocclusion and the signs and symptoms of TMD, significant evidence to suggest that functional or static occlusal factors cause TMD is lacking. TMD cannot be correlated with any specific type of malocclusion (23).

Studies indicate that the contribution of occlusal factors to the appearance of TMDs is mild. Only a few factors of static occlusion were significantly correlated with the signs of TMD (23). However, the study by Motta et al. (24) found that there was a statistically significant association between parafunctional habits and sinuses and/or TMD symptoms in adolescents. It should be noted that the study by Lemos et al. (20) showed that Class II malocclusion, overbite, and rotated teeth were correlated with the presence of clinical signs of joint TMD or the need for treatment, but that in general, occlusion may play a role as a cofactor in predisposing or perpetuating the different forms of TMD and should not be considered to be the main factor.

The absence of a disease-specific association between the features of dental occlusion and TMD has been observed, and there is no ground to hypothesize a major role of dental occlusion in the pathophysiology of TMDs. Thus, longitudinal studies should be performed to prove that there is a correlation between malocclusion and TMD (25-27).

\section{CONCLUSION}

There was a significant association between the 2 signs of TMD (crackling and bruxism) and Class II malocclusion. The signs and symptoms of TMD were more frequent in the patients who presented multiple teeth loss without malocclusion.

Ethics Committee Approval: This study was approved by Ethics committee of State University of Piauí (Approval No: 1.978.081).

Informed Consent: Written informed consent was obtained from the patients who agreed to take part in the study.

Peer-review: Externally peer-reviewed.

Author Contributions: Supervision - A.L.; Design - A.L., M.F.; Resources - A.L., M.F.; Materials - A.L., M.F.; Data Collection and/or Processing - A.L., M.F.; Analysis and/or Interpretation - A.L., M.F.; Literature Search - M.F.; Writing Manuscript - A.L., M.F.; Critical Review - A.L., M.F.

Conflict of Interest: The authors have no conflict of interest to declare.

Financial Disclosure: The authors declared that this study has received no financial support.

\section{REFERENCES}

1. Bishop K, Kelleher M, Briggs P, Joshi R. Wear now? An update on the etiology of tooth wear. Quintessence Int 1997; 28: 305-13.

2. Amantea DV, Novaes AP, Campolongo GS, Barros TP. The importance of postural evaluation in the patient with temporomandibular dysfunction. Acta Ortop Bras 2004; 12: 155-9. [Crossref]

3. Oliveira AS, Bermudez CC, Souza RA, Souza CMF, Dias EM, Castro CES, et al. Impact of pain on the lives of patients with temporomandibular dysfunction. J Appl Oral Sci 2003; 11: 138-43. [Crossref]

4. Verrett RG. Analyzing the etiology of an extremely worn dentition. J Prosthodont 2001; 10: 224-33. [Crossref]

5. Pullinger AG, Seligman DA. Analysis of occlusal variables, dental attrition, and age for distinguishing healthy controls from female patients with intracapstular emporomandibular disorders. J Prosthet Dent 2000; 83: 76-82. [Crossref]

6. Quinto CA. Classification and treatment of temporomandibular disorders: What is the role of speech therapists in the treatment of these disorders? Rev CEFAC 2000; 2: 15-22.

7. Delboni MEG, Abrão J. Study of TMD signs in asymptomatic orthodontic patients. Rev Dental Press Ortod Ortop Facial 2005; 10: 8896. [Crossref]

8. Wang C, Yin X. Occlusal risk factors associated with temporomandibular disorders in young adults with normal occlusions. Oral Surg Oral Med Oral Pathol Oral Radiol. 2012; 114: 419-23. [Crossref] 
9. Miot HA. Sample size in clinical and experimental trials. J. Vasc. Bras 2011; 10: 275-8.

10. Peres MA, Traebert J, Marcenes W. Calibration of examiners for dental caries epidemiology studies. Cad Saúde Pública 2001; 17: 15359. [Crossref]

11. Santos ECA, Bertoz FA, Pignatta LMB, Arantes FM. Clinical evaluation of signs and symptoms of temporomandibular dysfunction in children. Rev Dental Press Ortod Ortop Facial 2006; 11: 29-34. [Crossref]

12. Palaces CGF, Casado AC, Trigo AF, Pérez-Varela JC. Occlusion as an etiopatological factor in temporomandibular disorders. RCOE 2007; 12: 37-47. [Crossref]

13. Egermark I, Magnusson T, Carlsson GE. A 20-year follow-up of signs and symptoms of temporomandibular disorders and malocclusions in subjects with and without orthodontic treatment in childhood. Angle Orthod 2003; 73: 109-15.

14. Huang GJ, Leresche L, Critchlow CW, Martin MD, Drangsholt MT. Risk factors for diagnostic subgroups of painful temporomandibular disorders (TMD). J Dent Res 2002; 81: 284-8. [Crossref]

15. Luther F. TMD and occlusion part II. Damned if we do not? Functional occlusal problems: TMD epidemiology in a wider context. Br Dent J 2007; 202: 38-9. [Crossref]

16. Ciancaglini R, Gherlone EF, Redaelli S, Radaelli G.The distribution of occlusal contacts in the intercuspal position and temporomandibular disorder. J Oral Rehabil 2002; 29: 1082-90. [Crossref]

17. Landi N, Manfredini D, Tognini F, Romagnoli M, Bosco M. Quantification of the relative risk of multiple occlusal variables for muscle disorders of the stomatognathic system. J Prosthet Dent 2004; 92: 190-5. [Crossref]

18. Delboni MEG, Abrão J. Study of TMD signs in asymptomatic orthodontic patients. Rev Dental Press Ortod Ortop Facial 2005; 10: 8896. [Crossref]
19. McNamara JA, Seligman DA, Okeson JP. Occlusion, orthodontic treatment, and temporomandibular disorders: a review. J Orofac Pain 1995; 1: 73-90.

20. Lemos GA, Moreira VG, Forte FDS, Beltrão RTS, Batista AUD. Correlation between signs and symptoms of Temporomandibular Disorders (TMD) and severity of malocclusion. Rev Odontol UNESP 2015; 44: 175-180. [Crossref]

21. Teixeira ACB, Marcucci G, Luz JGC. Prevalence of malocclusions and anamnestic and clinical indices in patients with temporomandibular joint dysfunction. Rev Odontol Univ São Paulo 1999; 13: 251-6. [Crossref]

22. Henrikson T, Nilner M. Temporomandibular disorders, occlusion and orthodontic treatment. J Orthod 2003; 30: 129-37. [Crossref]

23. Mohlin B, Axelsson S, Paulin G, Pietilä T, Bondemark L, Brattström V, et al. TMD in relation to malocclusion and orthodontic treatment: $a$ systematic review. Angle Orthod 2007; 77: 542-8. [Crossref]

24. Motta LJ, Guedes CC, Santis TO, Fernandes KPS, Ferrari RAM, Bussadori SK. Association between parafunctional habits and signs and symptoms of temporomandibular dysfunction among adolescents. Oral Health Prev Dent 2013; 11: 3-7.

25. Badel T, Marotti M, Krolo I, Kern J, Keros J. Occlusion in patients with temporomandibular joint anterior disk displacement. Acta Clin Croat $2008 ; 47: 129-36$.

26. Murphy MK, MacBarb RF, Wong ME, Athanasiou KA. Temporomandibular Joint Disorders: A review of Etiology, Clinical Management, and Tissue Engeneering Strategies. Int J Oral Maxillofac Implants 2013; 28: e393-e414. [Crossref]

27. Manfredini D, Lombardo L, Siciliani G. Temporomandibular disorders and dental occlusion. A systematic review of association studies: end of an era? Journal of Oral Rehabilitation 2017; 44: 908-23. [Crossref] 